\title{
GLOBAL SOLUTIONS OF CERTAIN HYPERBOLIC SYSTEMS OF QUASI-LINEAR EQUATIONS
}

\author{
BY J. L. JOHNSON ${ }^{1}$ AND J. A. SMOLLER ${ }^{2}$ \\ Communicated by L. Cesari, March 23, 1967
}

We consider systems of the form

$$
u_{t}+f(v)_{x}=0, \quad v_{t}+g(u)_{x}=0,
$$

with initial data $(v(0, x), u(0, x))=\left(v_{0}(x), u_{0}(x)\right)$. Here $u$ and $v$ are functions of $t$ and $x, t \geqq 0,-\infty<x<\infty$, and $f$ and $g$ are $C^{2}$ functions of a single real variable. We assume that the system (1) is hyperbolic and genuinely nonlinear in the sense of Lax [4].

TheOREM 1. For each point $\left(v_{0}, u_{0}\right)$ in the $(v-u)$-plane, there exist two smooth curves $u=w(v)=w\left(v, v_{0}, u_{0}\right)$ and $u=s(v)=s\left(v, v_{0}, u_{0}\right)$, passing through $\left(v_{0}, u_{0}\right)$ defined for all $v \geqq v_{0}$ with the properties that $w^{\prime}(v)>0, s^{\prime}(v)<0$ and each point $(v, w(v))$ satisfies the Lax conditions for backward rarefaction waves [4], while each point $(v, s(v))$ satisfies the Lax conditions for forward shock waves [4].

In other words, the Riemann problem for (1) with initial data

$$
\begin{aligned}
\left(v_{0}(x), u_{0}(x)\right) & =\left(v_{0}, u_{0}\right), & & x<0, \\
& =\left(v_{1}, w\left(v_{1}\right)\right), & & x>0
\end{aligned}
$$

where $v_{1}>v_{0}$, can be solved by two constant states $\left(v_{0}, u_{0}\right)$ and $\left(v_{1}, w\left(v_{1}\right)\right)$ separated by a backward rarefaction wave. Similarly the Riemann problem for (1) with initial data

$$
\begin{aligned}
\left(v_{0}(x), u_{0}(x)\right) & =\left(v_{0}, u_{0}\right), & & x<0, \\
& =\left(v_{1}, s\left(v_{1}\right)\right), & & x>0
\end{aligned}
$$

where $v_{1}>v_{0}$ can be solved by two constant states $\left(v_{0}, u_{0}\right)$ and $\left(v_{1}, s\left(v_{1}\right)\right)$ separated by a forward shock wave.

Fix a point $\left(v_{0}, u_{0}\right)$ in $(v-u)$-space and let

$$
C\left(v_{0}, u_{0}\right)=\left\{(v, u): v \geqq v_{0}, \quad s\left(v, v_{0}, u_{0}\right) \leqq u \leqq w\left(v, v_{0}, u_{0}\right)\right\}
$$

Theorem 2. If $\left(v_{1}, u_{1}\right) \in C\left(v_{0}, u_{0}\right)$, then $C\left(v_{1}, u_{1}\right) \subset C\left(v_{0}, u_{0}\right)$.

One consequence of Theorem 2 is that the interaction of two forward shocks produces a forward shock and a backward rarefaction

${ }^{1}$ NSF Cooperative Fellow.

${ }^{2}$ Research supported in part by NSF Research Grant GP 3466. 
wave. (A similar result is valid for the interaction of two backward shocks.) In [3] this consequence is part of the hypothesis.

Theorem 3. Let one of the functions $v_{0}(x)$ and $u_{0}(x)$ be bounded and let them have the property that if $x_{1}<x_{2},\left(v_{2}, u_{2}\right) \in C\left(v_{1}, u_{1}\right)$, where $\left(v_{i}, u_{i}\right)$ $=\left(v_{0}\left(x_{i}\right), u_{0}\left(x_{i}\right)\right), i=1,2$. Then there exists a global solution, defined in $t \geqq 0$, of (1) with the initial data $(v(0, x), u(0, x))=\left(v_{0}(x), u_{0}(x)\right)$.

The condition on the initial data can be restated as follows. If $x_{1}<x_{2}$, then the Riemann problem for (1) with data

$$
\begin{aligned}
\left(v_{0}(x), u_{0}(x)\right) & =\left(v_{1}, u_{1}\right), & & x<0, \\
& =\left(v_{2}, u_{2}\right), & & x>0
\end{aligned}
$$

is solvable by a backward rarefaction wave and a forward shock.

Similar theorems can be proved for backward shocks and forward rarefaction waves.

Our methods are extensions of those in [5] where the case $g^{\prime \prime}(u)=0$ is considered. We obtain the solution as a limit of a sequence of solutions of initial-value problems for (1) with step data. We then show that the approximating solutions are uniformly bounded and have uniformly bounded variation in the sense of Tonelli-Cesari [1], on each compact set in $(t-x)$-space, $t \geqq 0$.

We remark that existence theorems of a somewhat different nature have recently been obtained in [2] and [3], by different methods.

\section{REFERENCES}

1. L. Cesari, Sulle funzioni a variazione limitata, Ann. Scuola Norm. Sup. Pisa (2) 5 (1936), 299-313.

2. J. Glimm, Solutions in the large for non-linear hyperbolic systems of equations, Comm. Pure Appl. Math. 18 (1965), 697-715.

3. J. Glimm and P. D. Lax, Decay of solutions of systems of hyperbolic conservation laws, Bull. Amer. Math. Soc. 73 (1967), 105.

4. P. D. Lax, Hyperbolic systems of conservation laws. II, Comm. Pure Appl. Math. 10 (1957), 537-566.

5. Zhang Tong and Guo Yu-fa, A class of initial value problems for systems of aerodynamic equations, Acta Math. Sinica 15 (1965), 386-396; English transl., Chinese Math. 7 (1965), 90-101.

The University of Michigan 